УДК 533.6.011, 621.694.2

\title{
OPTIMIZATION OF THE SYNTHESIS OF PACKING MACHINES BY THE EFFICIENCY CRITERIA
}

\author{
L. Kryvoplias-Volodina, O. Gavva, A. Derenivska \\ National University of Food Technologies
}

\begin{tabular}{l} 
Key words: \\
Technological processe \\
Optimization synthesis \\
Functional device \\
Functional mechatronic \\
module \\
The overall efficiency of \\
The equipment OEE \\
(Overall Equipment \\
Effectiveness) \\
\hline \multicolumn{1}{c}{ Article history: } \\
Received 04.09.2018 \\
Received in revised form \\
26.09.2018 \\
Accepted 17.10.2018
\end{tabular}

Corresponding author:

O. Gavva

E-mail:

npnuht@ukr.net

\begin{abstract}
In this article, the conditions for the synthesis of the packaging machine layout were developed. Development was carried out by a criterion evaluation of individual functional mechatronic modules (FMM). These modules were combined with two main groups of evaluations, which are calculated by the cost program developed by the authors. The analysis of the hierarchical structure of an individual functional modular subsystem for the FMM packing machine for small-piece products was presented. In accordance with the proposed example, the evaluation of the overall efficiency of the equipment OEE (Overall Equipment Effectiveness) of the technological processin in FMM for feeding a roll packaging material was performed. On the example of the FMM for feeding a roller packaging material for a packing machine, which had different functional devices (FDj), schemes and models for implementing multi-stage step-by-step multicriteria synthesis were developed. It was also proved the feasibility of using such schemes and models for different criteria of the optimization task. The use of the OEE criterion, which has aggregate properties and reflects the generalized evaluation of the FMMi with maxmin (minmax) criterion on the basis of the compromise principle was substantiated. This principle is based on the idea of optimality of the FMMi of the food packaging machine, with the subsequent addition of each of the following functional module. The optimization synthesis of structures and machines FMM drawing film for packaging small-piece products was conducted. The subprogramme the table in Exel Software for semi-automated mode solve the problems of synthesis optimization for selecting the layout of modules in the packaging equipmemt was developed. The results of theoretical research are adequate to actual technological processes, which is confirmed by experimental research.
\end{abstract}

DOI: $10.24263 / 2225-2924-2018-24-5-15$ 


\title{
ОПТИМІЗАЦІЯ СИНТЕЗУ ПАКУВАЛЬНИХ МАШИН ЗА КРИТЕРІЕМ ЕФЕКТИВНОСТІ
}

\author{
Л.О. Кривопляс-Володіна, О.М. Гавва, А.В. Деренівська \\ Начіональний університет харчових технологій
}

У статті розроблено умови синтезу компонувань пакувальної мамини на базі критеріальної оцінки окремих функиіональних мехатронних модулів (ФММ), об'єднаних двома основними групами очінок. Для цьвого було проведено математико-статистичний аналіз технічних і технологічних характеристик основних функиіональних модулей пакувальних машин та застосовані методи математичного розрахунку показника загальної ефективності обладнання OEE (Overall Equipment Effectiveness) з подальшою розробкою програми розрахунку ОЕЕ. Під комплексом технічних засобів розуміють сукупність технічних пристроїв, взаємозв'язаних між собою для виконання виробничого технологічного процесу пакування. Наведено аналіз ієрархічної структури окремої функиіональної модульної підсистеми для ФММ машини пакування дрібно-итучних харчових продуктів. Відповідно до запропонованого прикладу проведено очінювання за допомогою показника ОЕЕ технологічного прочесу ФММ подачі рулонного пакувального матеріалу. Розроблено схеми та моделі реалізаиї̈ багатоетапного покрокового багатокритеріального синтезу на прикладі ФММ подачі рулонного пакувального матеріалу для пакувальної машини із різними функиіональними пристроями $\left(Ф \Pi_{j}\right)$, обгрунтовано дочільність їх використання для різних критерї̈в задачі оптимізації.

Також обтрунтовано використання критерію ОЕЕ, який має сукупні властивості і відображає узагальнену оцінку ФММі із максимінним (мінімаксним) критерієм за принципом компромісу, що трунтується на ідеї оптимальності ФММ і машини для пакування харчових продуктів, при додаванні до ї̈ складу кожного наступного функиіонального модуля. Проведено оптимізаиійний синтез структури машини та ФММ протягування плівки для пакування дрібно-итучних виробів. Розроблено підпрограму-табличю ПП Ехеl для розв'язання задач оптимізаиійного синтезу у напівавтоматизованому режимі для вибору компоновки модулів у пакувальному обладнанні. Результати теоретичних досліджень є адекватними реальним технологічним процесам, що підтверджено експериментальними дослідженнями.

Ключові слова: технологічний процес, оптимізаиійний синтез, функиіональний пристрій, функціональний мехатронний модуль, показник загальної ефективності обладнання.

Постановка проблеми. Для скорочення витрат, пов'язаних із проектуванням, виготовленням, обслуговуванням пакувальних машин, потрібно вміти розрахувати їх повну ефективність. Показник загальної ефективності обладнання OEE (Overall Equipment Effectiveness) враховує номінальну продуктивність обладнання час його роботи, оцінює ефективність за різними параметрами. 
Структуру пакувальних машин можна навести сукупністю самостійно функціонуючих технічних систем - функціональні мехатронні модулі (ФММ), які складаються 3 окремих функціональних пристроїв (ФП) $[1 ; 2]$ Технічна характеристика ФММ визначається типом, складом та якістю елементів і функціональних підсистем, що взаємодіють між собою і об'єднані в єдину технічну систему для пакування харчового продукту.

Мета дослідження: розроблення умов синтезу компонувань пакувальної машини на базі критеріальної оцінки окремих ФММ, об'єднаних двома основними групами оцінок, які розраховують програмою витрат.

Матеріали і методи. У процесі дослідження було проведено математикостатистичний аналіз технічних i технологічних характеристик основних функціональних модулей пакувальних машин. Застосовані методи математичного розрахунку складових ОЕЕ. Завдання полягало у розробленні програми розрахунку OЕЕ, діалогове вікно якої наведено на рис. 1.

Під комплексом технічних засобів розуміють сукупність технічних пристроїв, взаємозв'язаних між собою для виконання виробничого технологічного процесу пакування.

Результати і обговорення. Здійснення оптимізаційного синтезу компонувань ПМ передбачає послідовне виконання ряду процедур, пов'язаних із ОЕЕ. Кожна з них полягає у розв'язанні певної локальної задачі, результати виконання якої є початковими даними для наступної [2-5]. Як приклад, наведемо аналіз ієрархічної структури окремої функціональної модульної підсистеми (рис. 2) для ФММ машини пакування дрібно-штучних харчових продуктів.

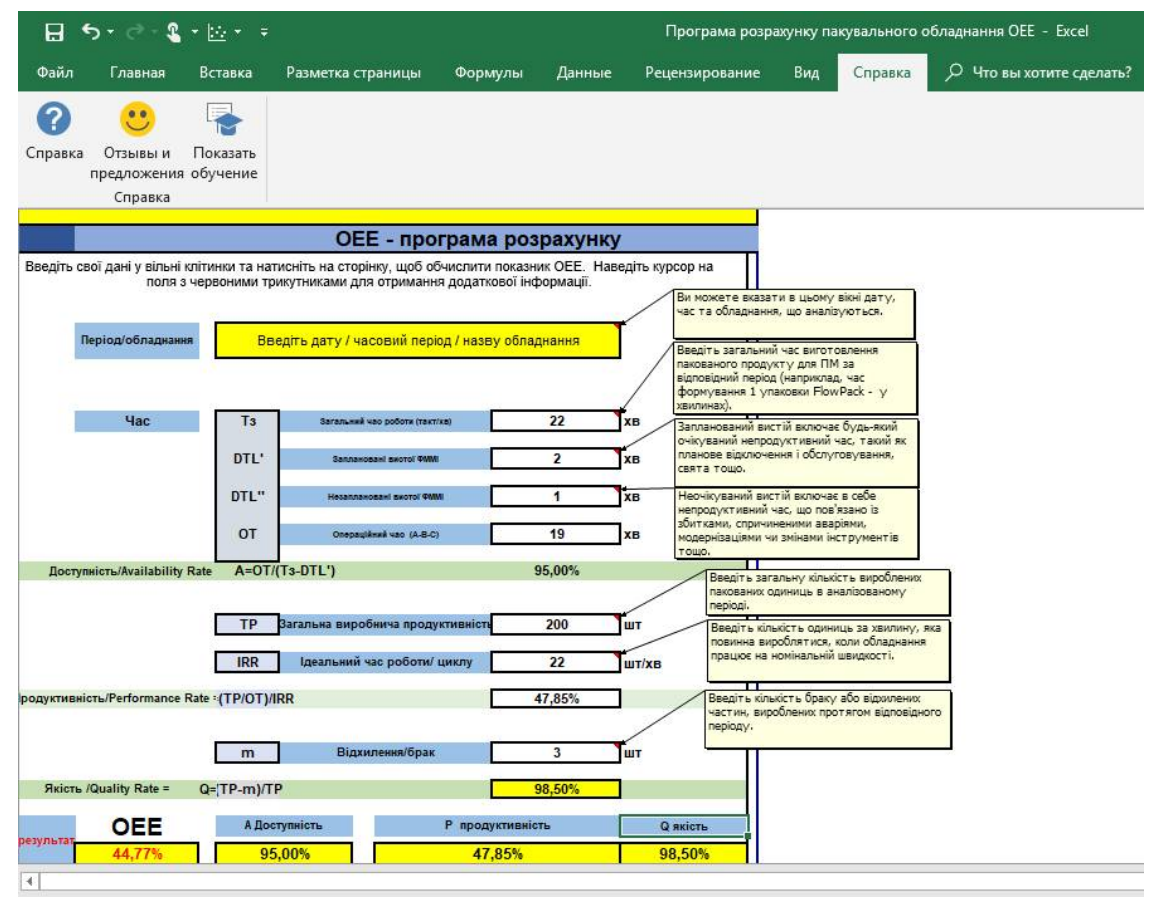

Рис. 1. Узагальнена програма розрахунку ОЕЕ для ПМ харчових продуктів 
Відповідно до запропонованого прикладу оцінювання ОЕЕ технологічного процесу, одним із перших починає працювати ФММ подачі рулонного пакувального матеріалу.

Враховуючи рекомендації [7; 8] щодо значення задовільного ОЕЕ для функціональних пристроїв пакувального обладнання, отримані розрахунки (рис. 2) дають можливість визначити оптимальну компоновку функціонального пристрою в структурі ФММ подачі рулонного пакувального матеріалу.

Принциповими особливостями процесів пакування харчових продуктів $\epsilon$ кінематика, динаміка руху об'єкта та невизначеність витрат, термінів та інших параметрів (рис. 3).

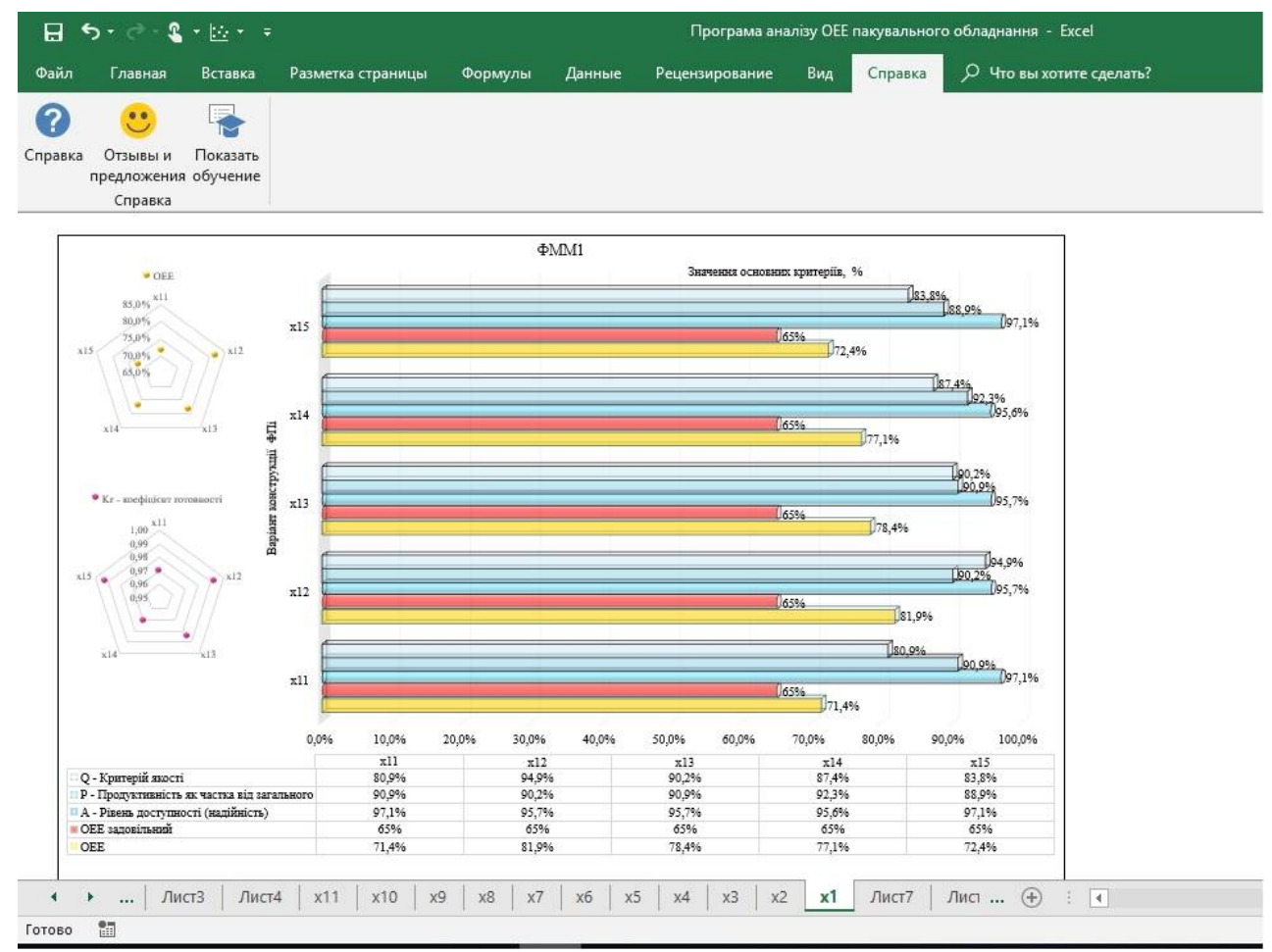

Рис. 2. Гістограма критеріальної оцінки ФП у складі ФММ — подачі рулонного пакувального матеріалу

Вектор $u(k)$ визначає керуючу дію на $k$-му етапі. Вектор $x(k) \epsilon$ елементом $n$-вимірного простору станів, який можна позначити через $X_{k}$, компонентами якого можуть бути як кількісні, так і якісні техніко-економічні характеристики ФММ у складі пакувальної машини:

$$
x(k) \in X_{k}(k=0,1, \ldots, N) .
$$

Вектор $u(k)$ може набувати значень із деякої заданої підмножини $U_{k}$ :

$$
u(k) \in U_{k}(k=0,1, \ldots, N) .
$$


Керуюча дія буде пов'язана відношенням:

$$
U(t)=S_{i}^{j}(t) \cdot E_{i}^{j}(t) \cdot I_{i}^{j}(t),
$$

де $S_{i}^{j}(t), E_{i}^{j}(t), I_{i}^{j}(t)$ - матеріальна, енергетична й інформаційна дія при

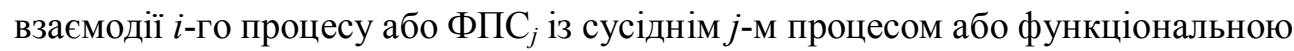
підсистемою у момент часу $t$.

Управління станом можна подати як суму рівнянь:

$$
U(t)=C\left(S_{i}^{j}\right)+C\left(E_{i}^{j}\right)+C\left(I_{i}^{j}\right),
$$

де $C\left(S_{i}^{j}\right), C\left(E_{i}^{j}\right), C\left(I_{i}^{j}\right)$ - вартість множини затрат матеріального, енергетичного й інформаційного типів відповідно.

При цьому можуть бути враховані обмеження на вектор станів $X_{k}$ та управлінь $U_{k}$,відповідно, набором нерівностей:

$$
\begin{gathered}
h_{j}(x(k), k) \geq 0\left(j=1, \ldots, s_{k} ; k=0,1, \ldots, N\right) ; \\
q_{i}(x(k), u(k), k) \geq 0\left(j=1, \ldots, m_{k} ; k=0,1, \ldots, N-1\right) .
\end{gathered}
$$

Обмеження можуть задаватися спільно на змінні управління і стани:

$$
q_{i}(x(k), u(k), k) \geq 0\left(j=1, \ldots, m_{k} ; k=0,1, \ldots, N-1\right) .
$$

Принцип оптимальності Р. Беллмана [9; 10] може бути використаний для пошуку рішення (оптимального управління) на етапах синтезу ФММ із застосуванням кластерної бібліотеки ФП для пакувальної машини.

Для випадку, коли ФПС переходить із стану $x(0)$ у стан $x(k)$ за $k$ кроків (етапів). Його можна записати у вигляді виразу:

$$
f_{k-l}\left(X_{\text {ФПСl }}\right)=U_{l+1}^{\max }\left[E_{l+1}\left(X_{\Phi \Pi C_{l}}, U_{l+1}\right)+f_{k-(l+1)}\left(X_{\Phi \Pi C_{l+1}}\right)\right],(l=\overline{0, k-1}),
$$

де $U_{l}=\left\{u_{l}(1), \ldots, u_{l}(m)\right\}$ - рішення (управління), яке вибране на $l$-му кроці; $X_{\Phi П C_{l}}=\left\{x_{l}(1), \ldots, x_{l}(m)\right\}-$ стан ФПС на $l$-му кроці; $E_{l+1}$ - безпосередній ефект, який досягається на $l$-му кроці; $f_{n-1}$ - оптимальне значення ефекту, який досягається за $k-l$ кроків; $k$ - кількість кроків.

При визначенні кожного наступного значення функції $f_{n-1}$ використовується значення функції $f_{n-(l+1)}$, отримане на попередньому кроці (етапі), й безпосереднє значення ефекту $E_{l+1}\left(X_{\Phi П C_{1}}, U_{l+1}\right)$, яке досягається в результаті вибору рішення $U_{l+1}$ при заданому стані системи $X_{\Phi ̆ C_{l}}$. Процес підрахунків значень функції $f_{n-1}(l=\overline{0, k-1})$ здійснюється за початковою умовою $f_{0}\left(X_{\Phi п C_{k}}\right)=0$, яка означає, що за межами кінцевого стану функціональної підсистеми виробу ефект дорівнює нулю. 


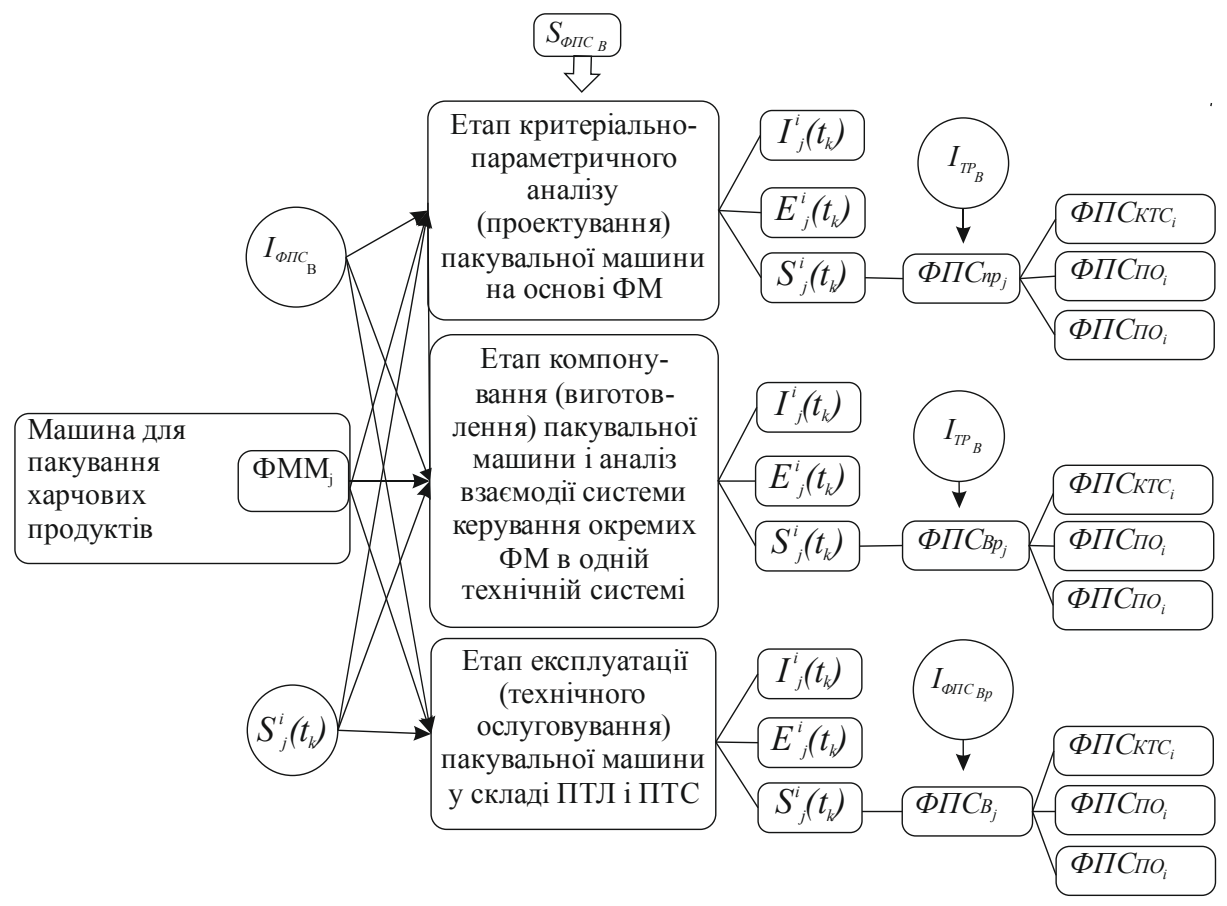

Рис. 3. Модель системи перетворень на етапах синтезу ФММ пакувальної машини: $\Phi{ }_{B j}$ - функціональна підсистема $j$-го ФММ; $\Phi П \mathrm{C}_{B p j}-$ функціональна підсистема виготовлення $j$-го ФММ; ФПС

$I_{\mathrm{TP}_{\mathrm{B}}}$ - інформація, що містить вимоги до ФММ; $I_{\Phi_{\text {пс }}}-$ інформація, що містить вимоги до функціональної підсистеми виготовлення ФММ; $I_{\text {Фпс в }}$ - інформація, що містить вимоги до умов виготовлення й експлуатації; $S_{j}^{i}\left(t_{k}\right)$ - матеріали і комплектуючі для виготовлення; $S_{\text {ФП в }}$ - виготовлений ФММ (синтезований із кластерів ФП пакувального обладнання)

Для вирішення такої задачі потрібно розглянути прототип ФММ. За умовою проведення порівняльного аналізу з існуючим обладнанням змодельовано автоматичний функціональний пристрій (АФП), розроблений авторами (рис. 4). Як дослідні зразки прийнято рулон пакувального матеріалу, масою $m=3$ кг; коефіцієнт тертя матеріалу по поверхні ролика $f_{1}=0,3$; ширина рулону - 300 мм; діаметр рулону -75 мм; запланована продуктивність $\Phi М М ~-~ 70$ пак/хв. Параметрами оброблення були тривалість $T$ операції перевантаження і траєкторія переміщення ролика (закріпленого на каретку пневмоциліндру), що оцінювалась по координатах $x, y$ і куту натягу $\varphi$. Значення $T_{i}(i=1,2,3, \ldots, n)$ заносились до розрахункової таблиці. Кількістю вимірів задавались на основі попередніх досліджень і розрахунків $(n=10)$. Отримані й оброблені результати експерименту порівняно 3 результатами аналітичних розрахунків, причому за вихідні дані прийнято параметри, іден- 
тичні експериментальним. Значення коефіцієнтів тертя пневмоцилідра, коефіцієнтів відновлення швидкості та міцнісні параметри упаковки визначались за відомими методиками $[1 ; 9 ; 10]$. Таким чином здійснено перевірку адекватності математичних моделей реальним процесам.

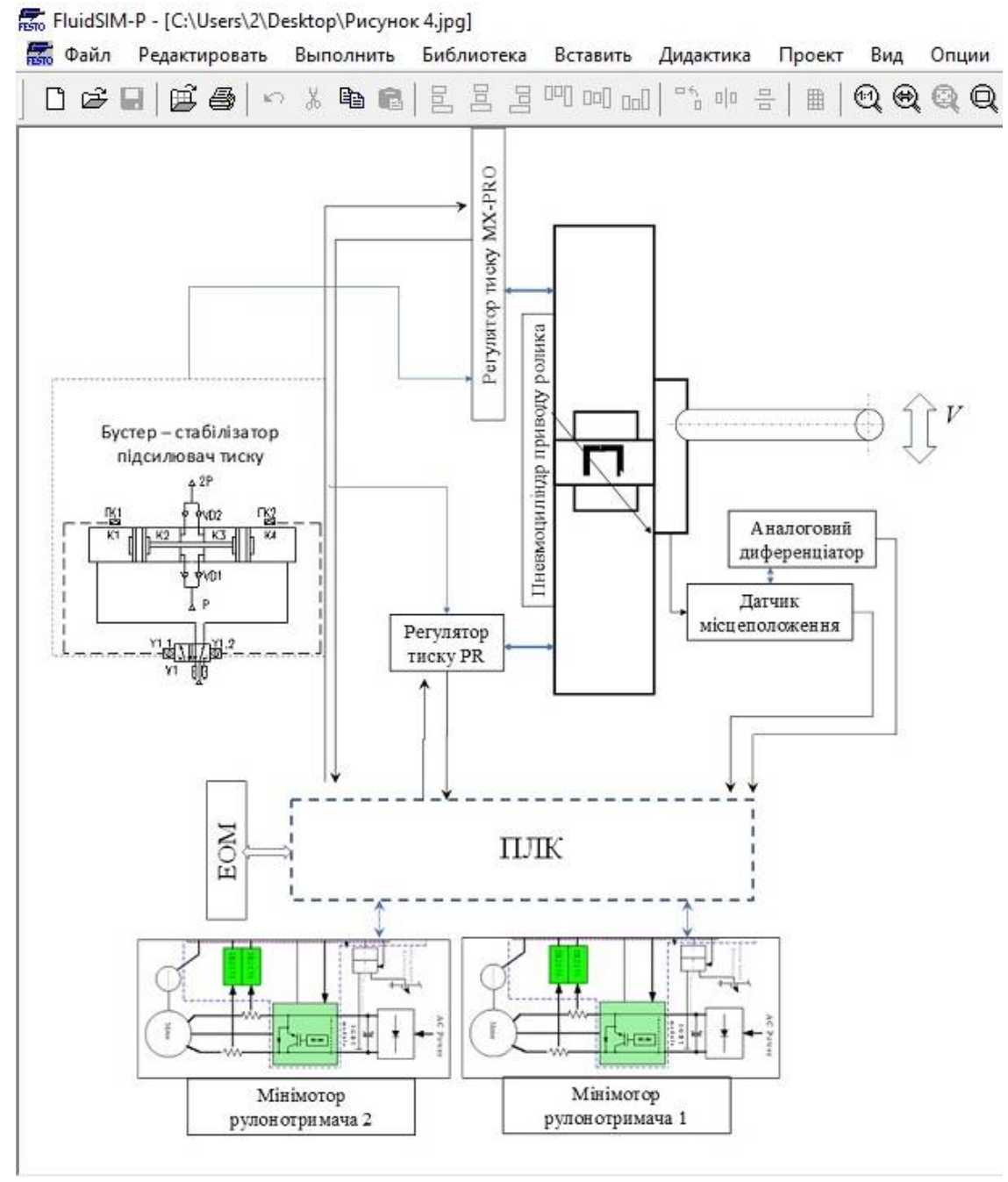

Рис. 4. Структурна схема стенда для експериментального дослідження ФММ подачі рулонного матеріалу в пакувальній машині

За умов, адекватних експерименту, розраховано тривалість операції переміщення каретки із натяжним роликом:

1. Експеримент 1 , де $T_{i}=0,65$ с. Тоді відносне відхилення тривалості операції, одержаної теоретичними дослідженнями, від експериментальних складає:

$$
\delta_{1}=\frac{0,71-0,65}{0,71} \cdot 100 \%=7,14 \% .
$$


2. Експеримент 2, де $T_{i}=0,97$ с . Тоді відносне відхилення тривалості операції, одержаної теоретичними дослідженнями, від експериментальних складає:

$$
\delta_{1}=\frac{1,05-0,97}{1,05} \cdot 100 \%=7,61 \% .
$$

На експериментальному стенді (рис. 3) послідовно було проведено серію дослідів із відповідним навантаженням ФММ. Зокрема, в ході досліджень приймались значення для магістрального тиску. В табл. наведені графіки зміни переміщення ролика натягування плівки від часу, в процесі його переміщення 3 робочою кареткою безштокового пневмоциліндра; графіки зміни тиску в робочих камерах пнемоцилідра при здійсненні робочого $\mathrm{i}$ холостого ходу; графіки зміни тиску на підвідній пневмомагістралі до ФММ із ФММ - пневматичного бустера (стабілізатора вхідного тиску з коефіцієнтом підсилення 2). Аналіз графіків показує, що характер зміни координати руху ролика, який визначався аналітично, відповідає реальному процесу перевантаження. Відхилення одержаних значень експериментальним шляхом від теоретичних не перевищували допустимі прийняті під час розв'язання подібних задач конструювання пакувальних машин (до 10...15\%).

Таблиця. Аналіз результатів експерименту із результатами теоретичних досліджень

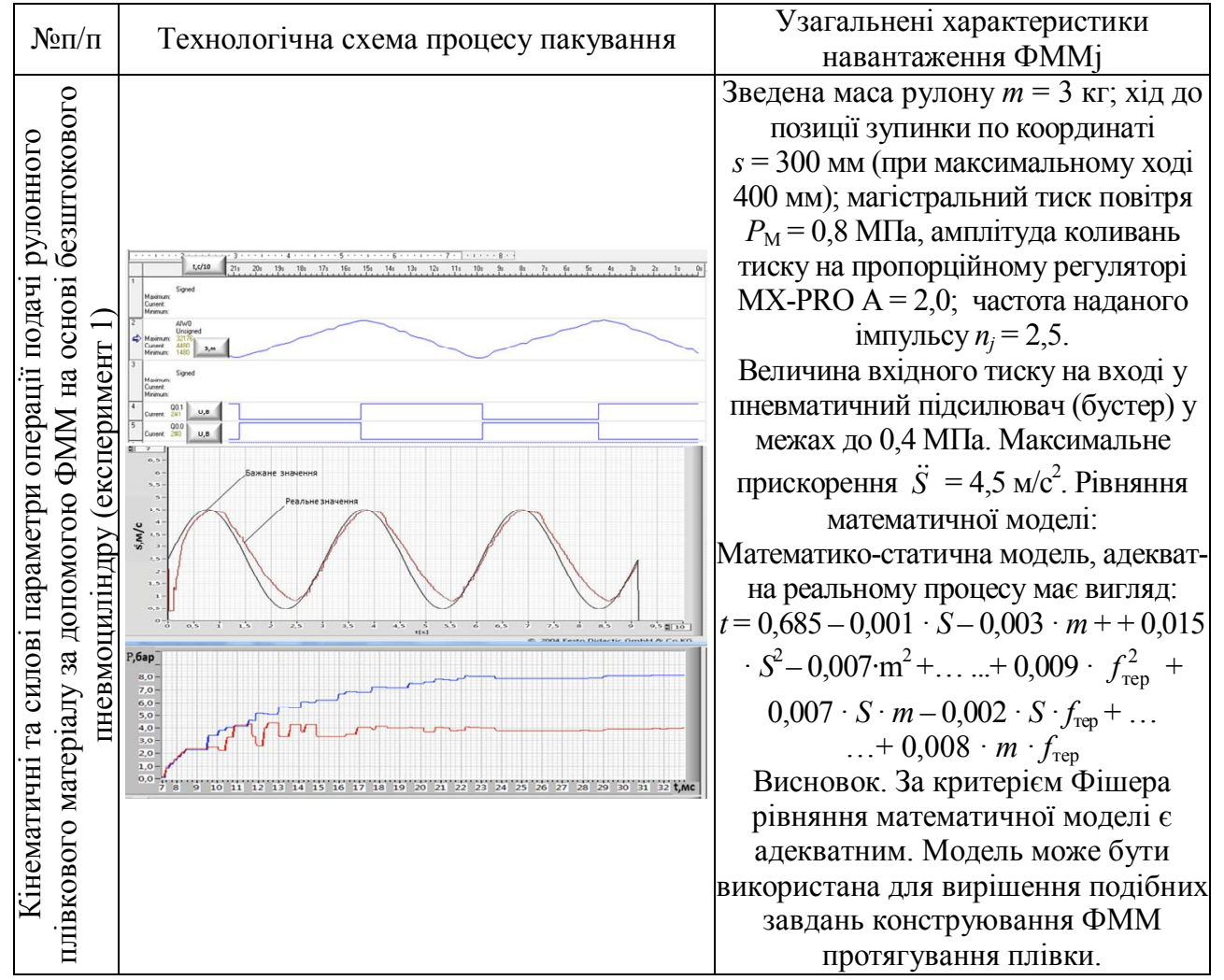




\section{Висновки}

1. Розроблено схеми та моделі реалізації багатоетапного покрокового багатокритеріального синтезу на прикладі ФММ подачі рулонного пакувального матеріалу для пакувальної машини із різними $Ф \prod_{j}$, обгрунтовано доцільність ï використання для різних критеріїв задачі оптимізації.

2. Обгрунтовано використання критерію OEЕ, який має сукупні властивості і відображає узагальнену оцінку $\Phi \mathrm{MM}_{i}$ із максимінним (мінімаксним) критерієм за принципом компромісу, який грунтується на ідеї оптимальності $\Phi M_{i}$ машини для пакування харчових продуктів, при додаванні до її складу кожного наступного функціонального модуля.

3. Проведено оптимізаційний синтез структури машини та ФММ протягування плівки для пакування дрібно-штучних виробів. Розроблено підпрограму-таблицю ПП Exel для розв'язання задач оптимізаційного синтезу у напівавтоматизованому режимі для вибору компоновки модулів у пакувальному обладнанні. Результати теоретичних досліджень є адекватними реальним технологічним процесам, що підтверджено експериментальними дослідженнями.

\section{Література}

1. Huang Samuel H. "Manufacturing Productivity improvement using effectiveness Metrics and simulation analysis". Int. J. Production Res. 2003. V. 41, No. 3. P. 513-527.

2. Som R.K. The quality revolution. University Press of America. NY. Practical sampling techniques. 2nd ed. Rev. and extended.Marcel Dakker, Inc. NY, 1996. P. 254-259.

3. Stamatis D.H. Six sigma and beyond: Statistical process control. St. Lucie Press. Boca Raton. FL. 2003. P. 125-132.

4. Mouradian, G. Handbook of QS-9000: Tooling and equipment certification. Society of Automotive Engineers. Inc.. Warrendale. PA. 2000. P. 136-147.

5. Кривопляс-Володіна Л.О., Гавва О.М. Інтегровані рішення компонувань пакувальних машин-автоматів у технологічних системах. Новітні технології пакування: XVI Науково-практична конференція молодих вчених. Додаток до журналу «Упаковка». Київ, 2017. C. $51-53$.

6. Stamatis D. Implementing the TE Supplement to QS-9000: The tooling and equipment supplier's handbook. Quality Resources. New York. 1998. 245 p.

7. Tsarouhas P. Implementation of total productive maintenance in food industry: a case study. Journal of Quality in Maintenance Engineering. United Kingdon. 2007. V. 13, No. 1. P. 5-18. URL: http://dx.doi.org/10.1108/13552510710735087.

8. Jacobs J.H. Characterization of operational time variability using effective process times. IEEE Transactions on Semiconductor Manufacturing, Eindhoven, 2003. V. 16, No. 3. P. $511-$ 520. URL: http://dx.doi.org/10.1109/TSM.2003.815215.

9. Busso C.M. Análise da aplicação de indicadores alternativos ao Overall Equipment Effectiveness (OEE) na gestão do desempenho global de uma fábrica. Produção, São Paulo, 2013. V. 23, No. 2. P. 205-225.

10. Nelson P. "Evolutionary Programming to Improve Yield and Overall Equipment Effectiveness of casting industry". Journal of Engineering and Applied Sciences. 2007. No. 2(12). P. $1735-1742$. 